\title{
Study of uric acid and lipid profile in recent onset essential hypertension
}

\author{
Jagannadha Phaneendra D.S ${ }^{1}$, Sujatha Pasula ${ }^{2, *}$, V. Sunanda ${ }^{3}$, D. N. Apparow ${ }^{4}$, Vennela kodali ${ }^{5}$ \\ ${ }^{1}$ Associate Professor, ${ }^{2}$ Assistant Professor, ${ }^{3}$ Professor and HOD, Dept. of Biochemistry, ${ }^{4}$ Senior Consultant, Dept. of General \\ medicine, ${ }^{5}$ Student, Kamineni Academy of Medical Sciences and Research Center, Hyderabad, Telangana, India
}

*Corresponding Author:

Email: drsujathapasula@gmail.com

Received: $27^{\text {th }}$ January, 2018

Accepted: 09 ${ }^{\text {th }}$ March, 2018

\begin{abstract}
Introduction: Hypertension is a major public health problem. Uric acid is emerging as one of the strongest risk factors for hypertension. Alteration in lipid profile has been identified as independent risk factor for hypertension.

Aim: The aim of our present study was to determine the association of uric acid and lipid profile with hypertension of recent onset. Materials and Methods: 45 subjects with age group between 20-50 yrs with recent onset essential hypertension were taken as test group. Control group comprised of 45 healthy, age and sex matched controls satisfying the exclusion criteria. Serum Uric acid, TC, HDL-C,LDL-C, TG'S were determined by enzymatic methods using commercially available kits on a fully automated analyzer. VLDL was a calculated parameter.

Results: In the test group the mean uric acid levels in males and females were $6.1 \pm 0.78 \mathrm{mg} / \mathrm{dl}$ and $5.5 \pm 0.93 \mathrm{mg} / \mathrm{dl} \mathrm{respectively}$. The mean uric acid levels among males and females in the control population was $4.2 \pm 0.81$ and $4.1 \pm 0.56 \mathrm{mg} / \mathrm{dl}$ respectively. A significant difference in uric acid levels between the test group and control group both among males $(\mathrm{p}=0.039)$ and females $(\mathrm{p}=$ 0.041 ) was observed. Among the lipid profile parameters. The mean Total cholesterol and Triglycerides were high in cases as compared to controls with p-values of 0.046 and 0.038 respectively. In test group higher mean values for HDL - C, LDL-C, VLDL were found as compared to controls but the increase was not statistically significant.

Conclusion: A significant association of UA with Hypertension both among males and females was observed in our study. Among the lipid profile parameters a significant association was found between Total cholesterol, Triglycerides and hypertension.
\end{abstract}

Keywords: Hypertension, Uric acid, Lipid profile.

\section{Introduction}

Hypertension is emerging as a major public health problem affecting 1 in every 4 individuals. ${ }^{1}$ Few studies suggest that one third of people are unaware of their hypertensive status, among the identified $40 \%$ are not on any medication, even among the patients identified and treated two thirds do not have their hypertension controlled to the level less than $140 / 90 \mathrm{mmHg}^{2}$ Hypertension is one of the most important risk factor for development of cerebral, cardiovascular and renal diseases. ${ }^{3}$ Worldwide increased blood pressure is estimated to cause 7.5 million deaths which accounts to $12.8 \%$ of total annual deaths. ${ }^{4}$ In India prevalence of hypertension varies from $17 \%-21 \% .^{5}$ In various studies on hypertension, hyperuricemia as a risk factor, marker was extensively studied. ${ }^{6-9}$ According to Canon et al serum uric acid levels greater than $6.5 \mathrm{mg} / \mathrm{dl}$ has been found in $25-40 \%$ of their hypertensive patients and a serum uric acid concentration of $5.5 \mathrm{mg} / \mathrm{dl}$ was found in the remaining $60 \%$ of hypertensive patients included in their study. A linear relationship between serum uric acid and systolic blood pressure was found by them. ${ }^{10}$ Lack of proper understanding exists as regards role of uric acid in causation of hypertension. Reduction of nitric oxide , Renin angiotensin aldosterone system activation might be the possible mechanisms according to some studies. ${ }^{11}$ Possible role of increased uric acid in causation of hypertension at an younger age group was suggested by some studies. ${ }^{6,7}$
Alteration in serum lipid profile has been identified as an independent risk factor for essential hypertension. ${ }^{12,13}$ An abnormal change in lipid profile in hypertensives as compared to normal population was shown in many studies but it lacks specificity. Some studies suggest that hypercholesterolemia potentiates the effect of vaso constrictors such as endothelin1 and endothelin 2 on endothelium reduces nitric oxide production causing vasoconstriction leading to hypertension. ${ }^{14}$ Some studies suggest that hypertension might increase lipid oxidation enzymes causing formation of oxidised LDL leading to atherogenesis. Whether dyslipidemia is cause of hypertension or is an effect of hypertension is not clearly known. The aim of our present study was to determine the association of uric acid and lipid profile with recent onset hypertension.

\section{Materials and Methods}

The present study was undertaken in Department of biochemistry Kamineni academy of medical sciences and research centre, Hyderabad. This was a case control study done in collaboration with department of General medicine of the same institute from May - Oct 2016. Prior to the commencement of the study institutional ethical clearance was taken. A total of 90 subjects were enrolled into this study. They were divided in to two groups. 45 subjects between age group 20-50yrs with recent onset of essential hypertension less than one year of duration were included in test group. 45 age and sex 
matched healthy subjects were included in control group. The participation of the subjects was on voluntary basis and informed consent was obtained.

The following were the Inclusion and exclusion criteria: Inclusion criteria:

1. Patients with Hypertension of less than one year duration

2. No target end organ damage.

3. Males and Females between age group of 20-50 yrs. Exclusion criteria:

1. Patients with hypertension more than one year duration.

2. Target end organ damage.

3. Patients suffering from type 1 and type 2 diabetes mellitus

4. Metabolic syndrome.

5. Body mass index greater than 30 .

6. Coronary artery diseases

7. Chronic kidney disease

8. Cerebro - vascular diseases

9. Metabolic diseases

10. Chronic liver disease.

11. Myocardial infarction.

12. Endocrine disorder - hypothyroid patients.

13. Psoriasis patients.

14. Chronic alcoholics.
15. Pregnant or lactating women.

16. Tuberculosis, any malignancy.

\section{Methods}

A $5 \mathrm{ml}$ of venous blood was obtained from the subjects after overnight fasting in plain tube. After clot formation the specimens were centrifuged at 3000rpm for $10 \mathrm{~min}$. The obtained serum was analysed for Uric acid (uricase method), Total cholesterol (CHOD-POD method), ${ }^{15}$ HDL-cholesterol(enzymatic method), ${ }^{15}$ LDLcholesterol (enzymatic method), ${ }^{15}$ Triglycerides(GPOPODmethod $)^{15}$ using commercial kits on a fully automated Mind ray BS 380 analyser. VLDL values were obtained by calculation (friedwalds formula).

\section{Statistical analysis}

Test results were analysed by using SPSS software version 17.0. Student $t$ - test as done to obtain ' $p$ '-value. Statistical significance was taken at a point of $\mathrm{p}$ value < or $=0.05$.

\section{Results}

It is a case control study done in 90 subjects were enrolled into this study.

Table 1: Demographic distribution of groups

\begin{tabular}{|l|c|c|c|}
\hline Characteristic & $\begin{array}{c}\text { Hypertensive } \\
\text { patients cases } \\
(\mathbf{n = 4 5})\end{array}$ & $\begin{array}{c}\text { Healthy } \\
\text { controls } \\
(\mathbf{n = 4 5})\end{array}$ & $\mathbf{p}$ - value \\
\hline Age & $41.2 \pm 5.3$ & $39.6 \pm 7.5$ & 0.13 \\
\hline Sex & $23(51.1)$ & $21(46.6)$ & 0.55 \\
Males & $22(48.8)$ & $24(53.3)$ & 0.62 \\
\hline Females & $139 \pm 6.2$ & $117 \pm 3.6$ & $0.04^{*}$ \\
\hline Systolic BP & $90 \pm 3.2$ & $79 \pm 2.6$ & $0.038^{*}$ \\
\hline
\end{tabular}

* P-value $<0.05$-significant

The mean age of control group and test group was $41.2 \pm 5.3$ and $39.6 \pm 7.5$ respectively. The test group included 23 males $(51.1 \%)$ and 22 females $(48.8 \%)$, the control group included 21 males (46.6\%) and 24 females (53.3\%) (Table 1). The mean Systolic blood pressure of test group and control group were and $139 \pm 6.2$ and $117 \pm 3.6 \mathrm{~mm}$ of $\mathrm{Hg}$ respectively $(\mathrm{p}=0.04)$. The mean Diastolic blood pressure of test group and control group were $90 \pm 3.2$ and $79 \pm 2.6$ $\mathrm{mm}$ of $\mathrm{Hg}$ respectively $(\mathrm{p}=0.038)$ (Table 1$)$.

Table 2: Normal ranges for Uric acid \& Lipid profile parameters

\begin{tabular}{|l|l|}
\hline Parameter & Normal range \\
\hline Uric acid (males) & $3.4-7.0 \mathrm{mg} / \mathrm{dl}$ \\
\hline Uric acid (Females) & $2.4-5.7 \mathrm{mg} / \mathrm{dl}$ \\
\hline Total Cholesterol & $<200 \mathrm{mg} / \mathrm{dl}$ \\
\hline HDL - Cholesterol & $40-60 \mathrm{mg} / \mathrm{dl}$ (males) \\
& $40-65 \mathrm{mg} / \mathrm{dl}$ (Females) \\
\hline LDL - Cholesterol & $<100 \mathrm{mg} / \mathrm{dl}$ \\
\hline VLDL - Cholesterol & $15-40 \mathrm{mg} / \mathrm{dl}$ \\
\hline Triglycerides & Less than $150 \mathrm{mg} / \mathrm{dl}$ \\
\hline
\end{tabular}


Table 3: Parameter wise distribution of results in groups

\begin{tabular}{|l|c|c|c|}
\hline Parameter & $\begin{array}{l}\text { Test group } \\
(\mathrm{n}=45)\end{array}$ & $\begin{array}{l}\text { Control group } \\
(\mathrm{n}=45)\end{array}$ & p- value \\
\hline Fasting Blood Sugar $(\mathrm{mg} / \mathrm{dl})$ & $97.1 \pm 5.4$ & $95.6 \pm 6.8$ & 0.11 \\
\hline TSH $(\mu \mathrm{IU} / \mathrm{ml})$ & $2.3 \pm 0.77$ & $2.2 \pm 0.92$ & 0.86 \\
\hline Total Cholesterol $(\mathrm{mg} / \mathrm{dl})$ & $192.6 \pm 28.6$ & $176.2 \pm 16.2$ & $0.046^{*}$ \\
\hline HDL-Cholesterol $(\mathrm{mg} / \mathrm{dl})$ & $45.6 \pm 5.1$ & $44.1 \pm 4.8$ & 0.162 \\
\hline LDL- Cholesterol $(\mathrm{mg} / \mathrm{dl})$ & $94.6 \pm 11.3$ & $87.4 \pm 9.6$ & 0.134 \\
\hline VLDL- Cholesterol $(\mathrm{mg} / \mathrm{dl})$ & $29.5 \pm 8.9$ & $23.4 \pm 6.1$ & 0.054 \\
\hline Triglycerides $(\mathrm{mg} / \mathrm{dl})$ & $150.6 \pm 40.9$ & $114.7 \pm 30.5$ & $0.038^{*}$ \\
\hline
\end{tabular}

$* \mathrm{P}$-value $<0.05$-significant

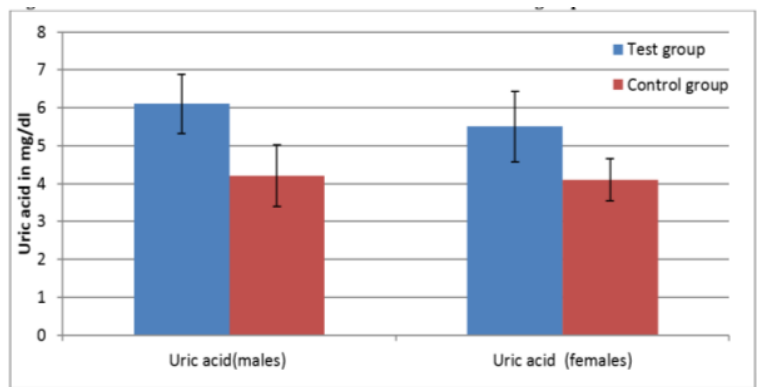

Fig 1: Gender wise distribution of uric acid levels in test and control group

Table 4: Showing comparision of uric acid levels (overall) among test and control groups

\begin{tabular}{|l|c|c|c|}
\hline Parameter & Test group & Control group & $\mathbf{P}$-value \\
\hline Uric acid & $5.8 \pm 0.85$ & $4.1 \pm 0.68$ & $0.040^{*}$ \\
\hline
\end{tabular}

Table 5: Showing comparision of uric acid levels among gender in test and control groups

\begin{tabular}{|l|c|c|c|}
\hline Parameter & Test group & Control group & P-value \\
\hline Uric acid (males) & $6.1 \pm 0.78$ & $4.2 \pm 0.81$ & $0.039^{*}$ \\
& & & \\
\hline Uric acid (females) & $5.5 \pm 0.93$ & $4.1 \pm 0.56$ & $0.041^{*}$ \\
\hline
\end{tabular}

* P-value $<0.05$-significant

In the test group the mean uric acid levels in males and females were $6.1 \pm 0.78 \mathrm{mg} / \mathrm{dl}$ and $5.5 \pm 0.93 \mathrm{mg} / \mathrm{dl}$ respectively. The mean uric acid levels among males and females in the control population was $4.2 \pm 0.81$ and $4.1 \pm$ $0.56 \mathrm{mg} / \mathrm{dl}$ respectively. A significant difference in uric acid levels between the test group and control group both among males $(\mathrm{p}=0.039)$ and females $(\mathrm{p}=0.041)$ was observed (Table 5).

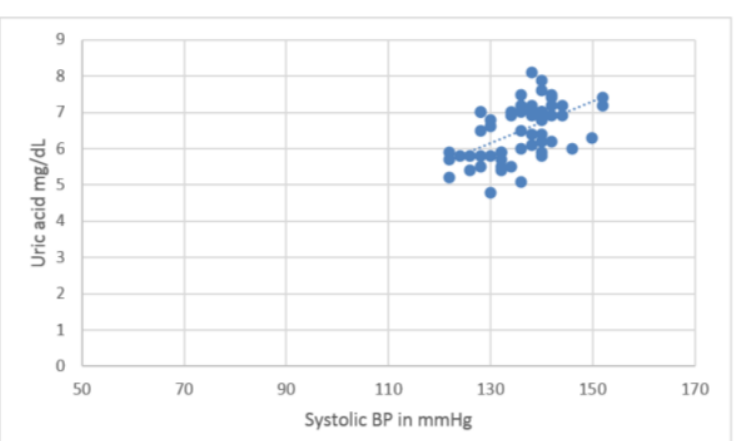

Fig. 2: Correlation between systolic BP and uric acid
There was positive correlation between systolic BP and uric acid

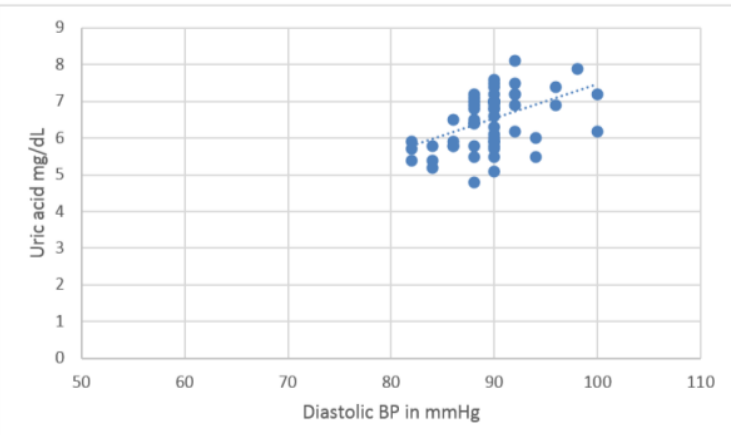

Fig. 3: Correlation between Diastolic BP and uric acid

There was a positive correlation between diastolic $\mathrm{BP}$ and uric acid.

The mean Total Cholesterol value of test group $(192.6 \pm 28.6)$ was higher as compared to controls $(176.2 \pm 16.2)$ and this difference in mean was statistically significant $(\mathrm{p}=0.046)$. The mean HDL- 
cholesterol values of test group was $45.6 \pm 5.1$ where as those of controls was $44.1 \pm 4.8$ but the difference was not statistically significant $(\mathrm{p}=0.162)$. The mean LDLcholesterol of test group was $94.6 \pm 11.3$ while in controls was $87.4 \pm 9.6$ Though there was an increase in LDL cholesterol in test group as compared to controls this difference was not statistically significant $(\mathrm{p}=0.134)$.

The mean VLDL value of test group $(29.5 \pm 8.9)$ was higher as compared to controls $(23.4 \pm 6.1)$ but the difference was not statistically significant $(\mathrm{p}=0.054)$. The mean Triglyceride values of test group was $150.6 \pm$ 40.9 , those of controls was $114.7 \pm 30.5$. This difference in mean was statistically significant $(\mathrm{p}=0.038)$ (Table 3 ).

\section{Discussion}

Hypertension is one of the causes of morbidity worldwide. ${ }^{6}$ In cardiovascular,cerebral and renal diseases hypertension is an important risk factor. ${ }^{3}$ In pathogenesis of hypertension hyperuricemia is an important risk factor. ${ }^{6}$

The proposed mechanism of increase in uric acid causing hypertension might be:

a) Constriction of renal vasculature by inhibition of Nitric oxide pathway and activation of renin angiotensin aldosterone pathway leading to blood pressure elevation. ${ }^{16}$

b) Vascular smooth muscle cell proliferation leading to irreversible damage to small renal vessel causing persistent hypertension. ${ }^{16}$

The mean age of participants included in the present study was 40.2 yrs. The test group showed an increase in uric acid levels $(5.8 \pm 0.85 \mathrm{mg} / \mathrm{dl})$ as compared to control group $(4.1 \pm 0.68 \mathrm{mg} / \mathrm{dl})$ and this difference in mean was statistically significant $(\mathrm{p}=0.04)$. More so among males a significant difference in Uric acid levels $(p=0.039)$ was found in test group as compared to control group. Even among females a significant difference in Uric acid levels $(\mathrm{p}=0.041)$ was found in test group as compared to control group.

Fredrick akbar mohammed was first to document an association of Uric acid with hypertension. ${ }^{17}$ Extensive research was done to determine mechanism of the uric acid induced hypertension but were inconclusive . Plasma uric acid level as a predictor of increased risk of hypertension was reported by Hunt et al in a prospective study done in Utah. ${ }^{9}$ Similar association between Uric acid and Hypertension was reported in japanese men by Taniguchi et al. ${ }^{18}$ A $20 \%$ increased risk of hypertension per $1 \mathrm{mg} / \mathrm{dl}$ increase of Uric acid were found by them. Eshwar Krishnan et $\mathrm{al}^{19}$ in a follow up study found that normotensive men with baseline hyperuricemia had an $80 \%$ excess risk for incident hypertension compared to those who had normal serum uric acid concentration. Another follow up study by sundstrom et $\mathrm{al}^{20}$ summarized uric acid as an independent risk factor of hypertension incidence. They observed a 13\% increase in risk for each $\mathrm{mg} / \mathrm{dl}$ increase in uric acid.
On contrary to other studies study by John P forman et $\mathrm{al}^{16}$ (mean age $=61 \mathrm{yr}$ ) showed no significant association of plasma uric acid with incident hypertension. In their study they specified that the role of hyperuricemia in causation of hypertension was prominent in the younger age group subjects. They stated that earlier studies showing the association of uric acid with hypertension were done in a population $<50 \mathrm{yrs}$ (sundstrom et al mean age $=48.7 \mathrm{yrs}$, Taniguchi et al mean age $=41 \mathrm{yrs}$ ). In a study done by N.N. Anand et $\mathrm{al}^{7}$ they discussed that the strength of association of uric acid with hypertension decreases with increase in age of the participants, suggesting Uric acid might have a role in causation of early onset hypertension in young subjects. This statement was supported by another study done by Sujeet Raina et al. ${ }^{8}$

Alteration in serum lipid levels has been identified as an independent risk factor for essential hypertension. Halperin et al ${ }^{13}$ showed that dyslipidemia in apparently healthy individuals leads to hypertension. Many studies have reported an abnormal change in Total cholesterol, Triglycerides and other lipid fractions more frequently in hypertensives as compared to normal population but the pattern of abnormality lacks specificity. Increase in Total Cholesterol, LDL-C, TG's was observed in hypertensives as compared to controls in studies done by Charles osuji et $\mathrm{al}^{21}$ Oladayo et al. ${ }^{22}$

Elevated Total cholesterol ( $\mathrm{p}=0.046)$ and Triglyceride levels $(p=0.038)$ were found in hypertensive patients as compared to controls in our present study and this increase was statistically significant. This was in accordance with studies done by Charles osujietal and Oladayo et al..$^{21,22}$ The pathological mechanism underlying this phenomenon is not clear.

No statistically significant increase was seen in VLDL, LDL-C in the hypertensive group as compared to controls in our study. This non significance might be due to the low sample size studied. The mean HDL-C values of hypertensive group and control group showed no major difference and this was in accordance with the earlier studies. ${ }^{21,22}$

\section{Conclusion}

A significant association between uric acid and hypertension was found in our study. More over the increase was also significant in males \& females of test group as compared to control group. There was also a significant association between Total cholesterol, triglyceride levels and hypertension in our study but other lipid parameters lack significant association. The low sample population included in this study might be one of the probable causes for this lack of association. Further studies on a large population groups might increase our understanding of uric acid and lipid profile with hypertension. The control of hyper uricemia in the young subjects by change in diet and medication might help in reduction of incidence of Hypertension. 


\section{References}

1. Chobanion AV, Bakris GL, Black HR, Cushman WC, Green LA, Izzo JL Jr, et al.The seventh report of joint national committee on prevention, detection, evaluation and treatment of high blood pressure:The $7^{\text {th }}$ report, JAMA 2003;289:2560-72.

2. Davidson's principles and practice of medicine $21^{\text {st }}$ edition.

3. Messerli FH, Williams B, Ritz E. Essential hypertension . Lancet 2007;370:591-603.

4. World Health Organisation Global Health Observatory Data 2016.

5. Park's textbook of preventive and social medicine. 22nd edition. WHO (2011), Global status report on Non communicable diseases, 2010.

6. P.RajavelMurugan and T. Padmavathi, A Study Of Prevalance Of Hyperuricemia In Hypertension. International Journal of Recent scientific:2015: Vol. 6,Issue, 7,pp.5257-9.

7. Anand N.N , padma V prasad A, AlamKC, Javed MS. Serum uric acid in new and recent onset primary hypertension J pharm bioallsci 2015;7;S4-8.

8. Raina S, Thakur S, Thakur S, Negi PC, Verma BS, Serum uric acid levels in hypertensive patients with and without metabolic syndrome the hills of Himachal Pradesh , India, J ObesMetab Res 2014;1:156-8.

9. Steven C. Hunt,Susan H.Stephenson, Paul N. Hopkins, and Roger R. Williams et al. Predictors of an increased risk of future hypertension in Utah. Hypertension 1991;17:969-76.

10. Cannon PJ, Stanson WB Demartini FE Sommers SE Laragh JH. Hyperuricemia in primary and renal hypertension N Engl J M 1966;275:457-64.

11. Corry DB, Eslami P, Yamamotok, Nyby MD, Makino H, et al. Uric acid stimulates vascular smooth muscle cell proliferation and oxidative stress via the vascular renin angiotensin system J Hypertens:2008 Feb;26(2):269-75.

12. R. R. Williams, S. C. Hunt, P. N. Hopkins et al., "Familial dyslipidemic hypertension. Evidence from 58 Utah families for a syndrome present in approximately $12 \%$ of patients with essential hypertension,"Journal of the American Medical Association: 1988:vol. 259, no. 24, pp.3579-86.

13. R. O. Halperin, H. D. Sesso, J. Ma, J. E. Buring, M. J. Stampfer, and J. M. Gaziano, "Dyslipidemia and the risk of incident hypertension in men," Hypertension, 2006: Jan;47(1):45-50.

14. Cardillo.C, KilkoeneCM, Cannon RO,Panza JA. Increased activiy of endogenous endothelin in patienis with hypercholesterolmia. J AM Coll Cardiol. 2000;36:1483-8.

15. Carl A. Burtis, Edward R. Ashwood David E. BrunsTeitz Fundamentals of clinical chemistry, $6^{\text {th }}$ edition pg.no. 371- 423.

16. John P. FormanHyon Choi and Gary C. Curhan et al Plasma uric acid level and risk for incident hypertension among men JASN january 2007 vol. 18 no. 1 287-92.

17. Mohamed FA. On chronic Bright's disease, and its essential symptom.Lancet 1879;1:399-401.

18. Taniguchi Y Hayashi T, Tsumura K, Endo G, Fjii S, Okada K. et al Serum Uric acid and the risk for hypertension and type 2 diabetes in Japanese men : The Osaka Health Survey JHypertens. 2001 Jul; 19(7): 120915.

19. EswarKrishnan, C.KentKwoh, H. Ralph Schumacher, Lewis Kuller et al Hyperuricemia and incidence of hypertension among men without metabolic syndrome. Hypertension.2007;49:298-303.

20. Johan Sundstrom, Lisa Sullivan, Ralph B.D Agostino, Daniel Levy, William B. Kannel, Ramachandran S. Vasan et al Relations of serum uric acid to longitudinal blood pressure tracking and hypertension incidence. Hypertension 2005;45:28-33.

21. Charles U. Osuji, Emeka G. Omejua, Emmanuel I. Onwubuya, and Gladys I. Ahaneku, "Serum Lipid Profile of Newly Diagnosed Hypertensive Patients in Nnewi, South-East Nigeria," International Journal of Hypertension, vol. 2012, Article ID 710486, 7 pages, 2012. doi: $10.1155 / 2012 / 710486$

22. Oladayo O. Oyelola, Ade A. Ajayi, MB, ChB,Rotimi O. Babalola,MB, BS, and Evan A. Stein et al. Plasma lipids, lipoproteins and Apolipoproteins in Nigerian Diabetes mellitus, Essential hypertension and hypertensive diabetic patients. JNatl Med Assoc.1995;87:113-8. 